\title{
A QUESTÃO DE ESCOLHA LINGUÍSTICA EM AMBIENTES DOMÉSTICOS NUM CONTEXTO MULTILINGUE DE MOÇAMBIQUE
}

\author{
Lourenço Mateus LINDONDE*
}

- RESUMO: O presente estudo examinou os padrões de escolhas linguísticas em ambientes domésticos de Montepuez, Moçambique, apoiando-se em abordagens sociolinguísticas que tratam da seleção linguística em contextos multilingues, nomeadamente as noções da diglossia e domínio. Os dados foram recolhidos através de um inquérito. O estudo observou que as várias línguas são usadas em ambientes caseiros, com maior predominância o Português e o Emakhuwa, sendo nula a relação entre a formalidade e a informalidade da situação. Assim, no ambiente caseiro a tendência é o uso das línguas maternas, que incluem o Português. Do ponto de vista teórico, o estudo concluiu que nenhuma abordagem é bastante e suficientemente forte para explicar o fenómeno da escolha linguística na totalidade, apelando para uma abordagem mais integrada, De facto, observou-se que o contexto real de comunicação é construído à medida que se faz a interação, pois se considera um processo negocial, que ocorre durante e não antes ou depois do ato comunicativo. Propõe-se estudos sobre escolhas linguísticas em outros espaços territoriais da província de Cabo Delgado, incluindo estudos subordinados a atitudes linguísticas com vista ao alargamento da informação relativa aos fatores que influenciam os usos linguísticos tanto em Montepuez quanto em outras regiões da província.

- PALAVRAS-CHAVE: Multilinguismo. Montepuez. Escolha linguística. Ambiente caseiro.

\section{Introdução}

Um dos grandes assuntos que tem preocupado a Sociolinguística é a questão dos usos linguísticos, tendo em conta que as comunidades linguísticas são eminentemente heterogêneas, havendo, portanto, um leque de possibilidades dentro do repertório da comunidade. Pretendo, neste artigo, apresentar os resultados de um estudo sobre usos linguísticos num contexto multilingue, em Montepuez, uma cidade da província de Cabo Delgado, tomando como referência o ambiente caseiro. ${ }^{1}$

\footnotetext{
Universidade Púnguè (UniPungue), Faculdade de Letras, Ciências Sociais e Humanidades. Cidade de Chimoio Moçambique. kenyal105@yahoo.com.br. ORCID: 0000-0001-5907-1119.

1 O artigo é parte da tese de doutoramento em linguística, que tinha como título "Padrões de Escolhas Linguísticas num Contexto multilingue de Moçambique: O Caso de Montepuez em Cabo Delgado" (LINDONDE, 2018).
} 
Na cidade de Montepuez, província de Cabo Delgado, existe uma comunidade, na qual há falantes de várias línguas, das quais se destacam Português, Emakhuwa, Shimakonde, Shingoni, Kiswahili e Kimwani (MAE, 2005; INE, 2010). O interesse pelo estudo dos usos linguísticos em ambientes domésticos de Montepuez emerge da pergunta “Quem fala que língua a quem e quando?" em contextos caracterizados por um multilinguismo alargado e relativamente estável ${ }^{2}$ (FISHMAN, 1965). Para Joshua Fishman, a seleção habitual de uma forma linguística está longe de ser uma questão aleatória ou deliberada de inclinação momentânea, pois ela é governada por fatores de controle. Inspirado pela pergunta formulada em Fishman (1965), procurei saber que língua ou línguas usavam os residentes de Montepuez nas suas interações em ambientes caseiros. Com esta pergunta, procurarei explicar as opções linguísticas de que se serviam os habitantes de Montepuez em ambientes domésticos de interação, tendo em conta as funções associadas às línguas.

O presente estudo teve como objetivos:

(1) identificar a língua ou as línguas mais usadas em ambientes caseiros de Montepuez,

(2) avaliar a influência da língua materna nas escolhas linguísticas dos residentes de Montepuez.

Ao privilegiar a apresentação dos dados relativos à variação do comportamento linguístico dos indivíduos de acordo com a língua materna, pretendi testar o postulado por Landweer (2008), segundo o qual o ambiente doméstico constitui um domínio indicador da vitalidade linguística, podendo ser o último a ser substituído por uma língua segunda.

Assim, a pesquisa assume a concepção de "escolha linguística", que pode ser entendida como um fenómeno que ocorre quando as pessoas têm o comando de duas ou mais línguas e, por conseguinte, elas têm de fazer escolhas de tipo quando, onde e a quem usar uma certa língua (FISHMAN, 1965; ADAMS; MATU; ONGARORA, 2012). A relevância desta pesquisa reside (1) na exploração de evidências sobre a dinâmica do mercado linguístico de Montepuez, podendo contribuir para a compreensão mais ampla do nível de implantação do Português e das línguas bantu nas comunidades locais, bem como (2) na ampliação do estudo para outro espaço geográfico deslocado da capital do país, conhecidos que são os estudos de Firmino (2002) e, de certa forma, tratado por Ngunga e Bavo (2011) e Companhia (2016). Por ser um tema pouco explorado no contexto de Moçambique, dada a primazia que tem sido dada aos estudos descritivos, pensamos ser oportuno e pertinente retomar esta linha de pesquisa. Aliás, como recomenda Firmino (2002), um melhor entendimento do funcionamento da diversidade linguística em África requer um exame dos dados referentes às práticas discursivas e ideológicas, o que precisa de ser estudado e não conjeturado. Com efeito,

Original: "This paper is primarily limited to a formal consideration of several descriptive and analytic variables which may contribute to an understanding of who speaks what language to whom and when in those settings that are characterized by widespread and relatively stable multilingualism characterized by widespread and relatively stable multilingualism" (FISHMAN, 1965, p. 67). 
Firmino (2002) apresenta relatos dos atores sociais sobre as línguas usadas na cidade de Maputo, Ngunga e Bavo (2011) descrevem as práticas linguísticas em seis distritos de Moçambique, enquanto que Companhia (2016) examina a língua de comunicação nas interações com os pais, irmãos, avós e amigos na cidade e província de Maputo.

\section{Revisão da literatura e enquadramento teórico}

Assumindo-se como um ramo da Sociolinguística, a Sociologia da Linguagem passou a concentrar-se em toda uma gama de tópicos relacionados com a organização social do comportamento linguístico, incluindo não só o uso da língua em si, mas também as atitudes linguísticas e comportamentos em relação à língua (FISHMAN, 1972). É com base nestes pressupostos que os estudos sobre usos linguísticos procuram determinar os fatores que, em situação de co-existência linguística na comunidade, explicam a escolha de uma forma linguística no lugar de outra (s), tendo em conta o repertório linguístico e as práticas sociais dentro das esferas da vida e atividade envolvidas. Diferentes autores abordam a questão da escolha linguística ${ }^{3}$ sob ponto de vista de diversas perspetivas. Alguns autores citados por Appel e Muysken (1987) tratam a questão da escolha linguística nas comunidades tendo em conta a perspetiva de variação intra-língua (BLOOM; GUMPERZ, 1972). No entanto, outros autores estudam a questão da escolha linguística seguindo a perspetiva da variação inter-linguística, o que pode ser confirmado, a título de exemplo, nos estudos de Greenfield (1972); Parasher (1980); Wherrit (1985), Borbély (2000); Adams, Matu e Ongarora (2012); Dumanige et al. (2013) ou Dersingh (2014). Outros autores discutem ainda a problemática da escolha linguística na perspetiva de política e planificação linguísticas em países multilingues (LOPES, 2013; FIRMINO, 2002; HEINE, 1990; VILELA, 2001). No presente trabalho, a questão da escolha linguística é abordada na perspetiva da variação inter-linguística. A opção por esta perspetiva fundamenta-se no facto de o estudo estar interessado nas situações de multilinguismo, em que os falantes têm que escolher uma língua em vez de outra (s), para se comunicarem num ambiente particular. Partindo deste pressuposto, a revisão da literatura incide sobre estudos orientados sobretudo pelas noções de diglossia e domínio.

\section{Exemplo de estudos orientados pela noção da diglossia}

Charles A. Ferguson propôs a noção da diglossia para mostrar que a escolha de uma variedade linguística deve ser explicada considerando alocações e funções sociais ou simbólicas a ela associadas. Assim, de acordo com Ferguson (1959),

Na literatura em língua inglesa este conceito é referido pela designação language choice, como por exemplo Appel e Muysken (1987). 
Diglossia é uma situação linguística relativamente estável em que, além dos dialetos primários da língua (que podem incluir um padrão ou padrões regionais), há uma variedade sobreposta, muito divergente, altamente codificada (amiúde gramaticalmente mais complexa), veículo de uma grande e respeitada parcela da literatura escrita, quer de um período anterior quer de outra comunidade de fala, e que é aprendida essencialmente pela educação formal e usada para a maioria dos propósitos escritos e formais, mas não é usada por nenhum segmento da comunidade para a conversação ordinária (FERGUSON, 1959, p. 244, tradução nossa). ${ }^{4}$

Por conseguinte, Charles Ferguson distingue uma variedade Alta, ou seja, High (H) e uma variedade Baixa, isto é, Low (L), sendo a primeira de prestígio (H), usada em âmbitos como serviços públicos e religiosos, escolarização e órgãos de informação, geralmente veículo de uma literatura culta muito ampla e muito valorizada, normalmente não é língua materna de ninguém, de modo que a sua aprendizagem se dá através da escolarização. A segunda, sem prestígio (L), é usada em ambiente familiar e de lazer, na literatura oral, normalmente adquirida como língua materna no contexto familiar, não é padronizada, pelo que não pode ser usada na educação formal,

Entretanto, Fishman (1967a) expandiu a noção de diglossia para cobrir situações em que existem duas línguas diferentes na comunidade de fala, as quais são mantidas separadas nas suas funções e usos. De acordo com o autor, trata-se de uma situação em que cada uma das línguas teria papéis diferentes e prestígio percebidos no espaço comumente partilhado. ${ }^{5}$ Por outro lado, Fishman (1972) admite que a diglossia ocorre também em sociedades que usam dialetos, registros separados ou funcionalmente diferenciados.

Conforme Stepkowska (2012), não obstante as diferenças de abordagem entre as concepções de diglossia aqui apresentadas, a distribuição em variedades High e Low constitui o ponto de convergência entre Charles Fergusson e Joshua Fishman, pelo que vários são autores que têm usado a noção de diglossia para examinar as escolhas linguísticas nas comunidades multilingues.

Vejamos alguns exemplos. Rubin (1968) apresenta uma descrição da situação do bilinguismo no Paraguai, em que duas línguas são usadas para a comunicação,

4 Original: Diglossia is a relatively stable language situation in which, in addition to the primary dialects of the language (which may include a standard or regional standards), there is a very divergent, highly codified (often grammatically more complex) superposed variety, the vehicle of a large and respected body of written literature, either of an earlier period or in another speech community, which is learned largely by formal education and is used for most written and formal spoken purposes but is not used by any sector of the community for ordinary conversation (FERGUSON, 1959, p. 244).

5 Original: Thus, two or more languages or language varieties can coexist in a given locality, each being supported by its corresponding sources. If one set of such supports prevails in some domains, while an alternative set becomes prevalent in other domains for a social group, so that the use of one of the two languages or varieties known by the members of that group is clearly favored and largely considered as proper for any domain, then a diglossic situation is said to exist (FERGUSON, 1972). 
nomeadamente o Espanhol (com estatuto de língua oficial, língua de negócios, e meio da educação superior, usada em ocasiões formais e nas interações com estrangeiros e superiores, bem como na igreja) e o Guarani (língua indígena, usada no discurso informal na família, com amigos, com serventes, bem como na maioria das ocasiões casuais fora das cidades e vilas e ensino primário).

Petzell (2012) descreve a situação linguística na Tanzânia em termos de diglossia entre o Swahili, línguas locais étnicas minoritárias e o Inglês. De acordo com Malin Petzell, a língua Swahili é usada em todo o país, mesmo em áreas isoladas e penetrou profundamente na sociedade tanzaniana, pois é a língua predominante em todos os ambientes públicos. Em contrapartida, Petzell (2012) reporta que as línguas minoritárias são faladas apenas em casa, sendo severamente ameaçadas pelo Swahili. Em ambientes públicos, as línguas minoritárias não são de todo ouvidas, pelo que o seu uso é proibido na educação e desencorajado em reuniões públicas e religiosas. Ademais, as línguas minoritárias não são usadas por nenhuma estação de rádio ou televisão e não existem jornais publicados nestas línguas.

Por seu turno, analisando a diglossia na Suíça, Stepkowska (2012) procurou mostrar em que medida o Alemão suíço, exemplificado por Ferguson (1959) como uma forma Low se tornou uma variedade Baixa com prestígio. De acordo com o autor, durante séculos os suíços conseguiram manter um equilíbrio entre as suas variedades dialetais e o Alemão padrão, evitando permanentemente a sua fusão. Foi na época da governação nazi que os alemães suíços buscaram refúgio na sua própria língua. Por conseguinte, o Alemão suíço entrou em muitas esferas da vida pública, onde nunca perdeu a posição.

Como é do conhecimento geral, Moçambique é um país multilingue, pois, para além do Português, língua oficial, existem neste país, de acordo com o Atlas Geográfico produzido pelo Ministério da Educação «15 unidades linguísticas, nomeadamente Makua, Lomwe, Merende, Mwani, Yao, Makonde, Nyanja, Sena, Nyungwe, Shona, Changana, Tswa, Ronga, Chopi e Bitonga (FIRMINO, 1998). No entanto, este mapa linguístico é, de certa forma, contrariado por Ngunga e Bavo (2011) que apresentam uma situação linguística caracterizada por cerca de 21 línguas do grupo bantu, para além da língua de sinais.

Com base no estatuto e funções sociais associadas ao Português e às línguas bantu, é de esperar que, no ambiente caseiro, os falantes recorram mais às línguas autóctones para se comunicarem com os familiares. Por conseguinte, foi formulada uma hipótese, segundo a qual em ambientes informais como casa, os residentes de Montepuez usam predominantemente as línguas bantu ${ }^{6}$ nas interações com os membros da família. $\mathrm{Na}$ formulação desta hipótese, parti do pressuposto de que o Português é língua oficial (ASSEMBLEIA DA REPÚBLICA, 2004), associado às situações oficiais e/ou formais, contrariamente às línguas bantu, cujo uso se restringe predominantemente aos ambientes familiares informais (FIRMINO, 2002; NGUNGA; BAVO, 2011).

As línguas bantu consideradas neste estudo são Emakhuwa, Shimakonde, Kiwsahili, Shingoni e Kimwani. 


\section{Exemplo de estudos orientados pela noção de domínio}

Fishman (1965), no seu artigo "Quem fala que língua a quem e quando", usa a noção de domínio para mostrar que existem certos contextos institucionais, nos quais o uso de uma variedade de língua específica é provável que seja mais apropriada do que outra. De acordo com este autor, domínios são tidos como constelações de fatores que incluem localização, que se refere ao lugar onde se realiza a interação, tópico, que se refere ao assunto de que se fala e participantes, que se refere a pessoas envolvidas na interação. Parafraseando Joshua Fishman, podemos dizer que a escolha linguística depende da pessoa a quem se fala, do assunto de que se fala e do local onde a conversa tem lugar, pelo que a combinação destes diferentes fatores configura diferentes tipos de domínios com respetivos usos linguísticos apropriados.

Um dos estudos mais citados por vários autores é atribuído a Greenfield (1972), realizado na comunidade porto riquenha de Nova Iorque. Neste estudo, o autor constatou que o Espanhol (língua materna dos informantes) era mais preferido no domínio da família, enquanto o Inglês era mais favorável ao domínio do trabalho e da educação. Por seu turno, Parasher (1980) realizou um estudo sobre escolhas linguísticas, através de um inquérito que envolveu 350 pessoas educadas em duas cidades na parte sul da Índia. $\mathrm{O}$ estudo constatou que a língua materna era mais usada no domínio familiar, enquanto o Inglês obteve maior pontuação nos domínios da educação, governo, e emprego. Por outro lado, o Inglês pareceu forte nos domínios de amizade e vizinhança.

Autores como Adams, Matu e Ongarora (2012) discutem os usos linguísticos em ambiente doméstico no bairro Kibera, no Quénia, tendo Kinubi como língua originária, mas onde também se falam outras línguas, minoritárias, tais como Lulya, Luo, Kikuyo, para além do Kiswahili, língua nacional franca. O estudo pretendia mostrar que a presença do multilinguismo em Kibera não causava nenhum efeito negativo sobre a língua Kinubi. Com efeito, dos 4 entrevistados, 3 mostraram-se favoráveis ao uso de Kinubi em casa com seus familiares, mostrando que o ambiente doméstico constitui um domínio indicador da vitalidade linguística, podendo ser o último a ser substituído por uma língua segunda (LANDWEER, 2008).

Entretanto, Haberland (2005) considera que é difícil aplicar o conceito de domínio àquelas situações em que a alternância de código faz parte do repertório linguístico dos interlocutores. Nestes casos, as línguas às vezes têm que ser escolhidas para cada enunciado e, às vezes, até mesmo nas declarações, o que, para o autor, não significa qualquer distribuição aleatória de língua, pois existem padrões reconhecíveis, mas eles não podem ser atribuídos a domínios diferentes, a menos que se considerem padrões de alternância de código como uma opção em situação de escolha linguística.

Em síntese considero, de um modo geral, que todas as teorias tratam, de alguma forma, o mesmo assunto, ou seja, a questão da escolha linguística, diferindo entre si na ênfase que é dada aos elementos envolvidos. Enquanto alguns focalizam sobre a língua em si, outros enfatizam a localização, tópico e participantes. Por outras palavras, nenhuma das várias abordagens é suficientemente forte para explicar o fenómeno da 
escolha linguística na sua totalidade. Com efeito, cada uma das abordagens salienta um certo aspeto inerente à interação comunicativa que, quando combinados, fornecem uma visão holística, embora também possa não ser totalmente satisfatória para explicar o fenómeno em estudo.

Em consequência destes fatos, a noção do domínio surge como a mais abrangente em comparação com as restantes abordagens sobre as escolhas linguísticas em contextos multilingues. A abrangência da noção de domínio reside no facto de incorporar elementos contextuais como localização, tópicos e participantes, os quais aparecem refletidos nas abordagens baseadas na noção da diglossia. Portanto, o presente estudo adota a noção de domínio, como conceito chave, pois congrega elementos das várias abordagens, sendo por isso que se assume, do ponto de vista teórico, um carácter eclético.

\section{Aspectos metodológicos}

Para a recolha dos dados, o estudo recorreu sobretudo ao inquérito. Por opção, as pessoas foram inquiridas a partir de diferentes casas selecionadas para o efeito. Para a concretização dos objetivos definidos no âmbito do inquérito, foi constituída uma amostra através do método de amostragem não probabilística. Tratou-se de uma pesquisa em que o recurso à quantificação dos dados serviu apenas para suportar a descrição dos fatos linguísticos constatados, daí que a componente estatística não tenha sido rigorosamente tratada na apresentação dos resultados da investigação. Como consequência destas opções metodológicas, os valores percentuais dizem respeito apenas ao uso de uma língua, não permitindo comparações.

Com efeito, servi-me de uma amostra acidental (FORTIN; CÔTÉ; VASSANDJÉE, 1999), que tem a vantagem de ser simples de organizar e pouco onerosa, embora limite a generalização dos resultados, uma vez que tem o risco de ser menos representativa do que a amostragem probabilística, quer do ponto de vista de grupos sociais, quer do ponto de vista de distribuição dos inquiridos pelos bairros.

De acordo com Fortin, Côté e Vassandjée (1999), os sujeitos submetidos ao inquérito são incluídos no estudo à medida que se apresentam no local preciso até a amostra atingir o tamanho desejado. Para atingir os informantes, contactei as chefias dos bairros, ${ }^{7}$ ou seja, os secretários dos bairros, a quem se solicitou a indicação de casas ou famílias sobre as quais o inquérito iria incidir. Por conseguinte, é seguinte a distribuição por bairros do número de casas abrangidas: Bairro Cimento (7), Nacate (8), Napai (66), Mirige (85), Nihula (27), Matunda (8), Mahipa (11), Ncoripo (23), Matuto (30), Namueto (7), Nicuapa (6), Pitimpini (13), Melapane (8), Matico (1) e Nancaramo B (1), totalizando 301 unidades residenciais.

No contexto de Moçambique, um Bairro é uma divisão administrativa de cidades e vilas, cujo tamanho varia de acordo com a realidade. 


\section{Estudo das escolhas linguísticas em Montepuez/Moçambique}

\section{Apresentação dos resultados do inquérito}

Como foi referido, a pesquisa de base foi realizada na cidade de Montepuez, a Sul da Província de Cabo Delgado, a $210 \mathrm{~km}$ da capital provincial, Pemba, tendo como população alvo os seus residentes. Em 301 casas, foram inquiridos 682 residentes, dos quais $54,5 \%$ são do género masculino e 45,5\% são do género feminino, com idades compreendidas entre 6 e 75 anos, distribuídos por três faixas etárias, designadamente dos 6 aos 14 anos, dos 15 aos 34 anos e dos 35 aos 75 anos de idade, conforme a Tabela 1 , que a seguir se apresenta.

Tabela 1 - Distribuição dos inquiridos por faixas etárias

\begin{tabular}{ccc}
\hline Faixas etários & Nr de inquiridos & Percentagem \\
\hline 6-14 anos & 112 & 16,4 \\
\hline 15-34 anos & 359 & 52,6 \\
\hline 35-75 anos & 211 & 31,0 \\
\hline Total & $\mathbf{6 8 2}$ & $\mathbf{1 0 0}$ \\
\hline
\end{tabular}

Fonte: Elaboração própria.

No estudo dos usos linguísticos em Montepuz, os inquiridos foram levados a pronunciarem-se sobre todas as línguas consideradas no estudo, uma por uma. Com efeito, perguntei aos sujeitos inquiridos se usavam Português, Emakhuwa, Shimakonde, Shingoni, Kiswahili e Kimwani em casa com seus familiares. ${ }^{8}$, o que, como afirmei anteriormente, foi feito com base em perguntas separadas como "Você costuma falar Português nas seguintes situações?” (em casa, na escola, no serviço, no mercado/loja, no comício popular, na igreja, na mesquita, na evocação dos espíritos dos antepassados e nas cerimónias dos ritos de iniciação). ${ }^{9}$

Para compreender as escolhas linguísticas dos indivíduos, comecei por agregar os dados por tendências gerais com vista a reunir as informações relativas à língua ou às línguas mais ou menos usadas pelos inquiridos em ambiente caseiro, independentemente de outros fatores sociais que possam influenciar as escolhas linguísticas dos inquiridos neste contexto de interação social. A Tabela 2, que se segue, ilustra as tendências gerais das escolhas linguísticas dos inquiridos em ambientes caseiros.

\footnotetext{
8 A inclusão destas línguas na grelha das perguntas relativa às escolhas linguísticas dos indivíduos em ambientes domésticos baseou-se no mapa linguístico proposto em Mae (2005) e Ine (2010).

9 As diferentes opções, que correspondem a diferentes domínios de interação, vinham inseridas numa tabela, onde o pesquisador marcava as respostas com $\mathrm{X}$.
} 
Tabela 2 - Usos linguísticos em ambientes domésticos (Dados gerais)

\begin{tabular}{cccccccccc}
\hline \multirow{2}{*}{ Línguas } & \multirow{2}{*}{ Usa a língua } & \multicolumn{2}{c}{ Não usa a } & \multicolumn{2}{c}{$\begin{array}{c}\text { Não } \\
\text { língua }\end{array}$} & \multicolumn{2}{c}{ Aplicável } & & \multicolumn{2}{c}{ Total } \\
& & fr. & $\%$ & fr. & $\%$ & fr. & $\%$ & Nr & $\%$ \\
\hline Português & 492 & 72,1 & 186 & 27,3 & 4 & 0.6 & 682 & 100 \\
\hline Emakhuwa & 624 & 91,5 & 54 & 7,9 & 4 & 0.6 & 682 & 100 \\
\hline Shimakonde & 83 & 12,2 & 592 & 86,8 & 7 & 1 & 682 & 100 \\
\hline Shingoni & 31 & 4,5 & 537 & 78,7 & 14 & 2.1 & 682 & 100 \\
\hline Kiswahili & 58 & 8,5 & 610 & 89,4 & 14 & 2.1 & 682 & 100 \\
\hline Kimwani & 192 & 28,2 & 646 & 94,7 & 4 & 0.6 & 682 & 100 \\
\hline
\end{tabular}

Fonte: Elaboração própria.

Os dados gerais mostram que, dos 682 inquiridos, 72,1\% declararam que usavam Português, enquanto que 91,\% reconheceram que usavam Emakhuwa em casa. Segundo as declarações dos inquiridos, Shimakonde, com 12,2\%, Shingoni, com 4,5\%, Kimwani, com $8,5 \%$ e Kiswahili com $28,2 \%$, tendem a ser as línguas menos usadas em ambientes caseiros, de acordo com as declarações dos informantes.

No entanto, constata-se que, quando as respostas foram dispostas considerando os indivíduos separados pela língua materna ${ }^{10}$ por eles declarada, há tendência para muitos reconhecerem que usam a sua L1 no ambiente doméstico. ${ }^{11}$

Com efeito, apresentam-se os resultados relativos à variação do comportamento linguístico dos falantes em ambientes caseiros, tendo em conta a variável "língua materna", de acordo com as declarações dos indivíduos. ${ }^{12}$

Entre os 7 inquiridos, cuja L1 é Português, todos declararam que usavam esta língua em casa com familiares; dos 569 inquiridos falantes do Emakhuwa como L1, 96,3\% disseram que a usavam em ambiente caseiro; dos 45 falantes do Shimakonde como L1, 86,7\% reconheceram que a usavam em casa com familiares; dos 22 inquiridos cuja L1 é Shingoni, 72,7\% afirmaram que usavam esta língua no ambiente doméstico; dos 5 falantes do Kiswahili como L1, todos disseram que usavam esta língua em casa; por último, entre os 19 falantes do Kimwani como L1, apenas 47\% declararam que a usavam em ambiente caseiro. No entanto, um segmento considerável dos inquiridos reconheceu que não usava a língua materna em ambientes domésticos, nomeadamente

10 A expressão "língua materna", ou simplesmente L1, tem sido usadas em oposição a L2, a EXPRESSÃO "LÍNGUA MATERNA" no contexto de Moçambique, deve ser entendida como a primeira língua com que a criança inicia a sua socialização, portanto a sua língua nativa (LINDONDE, 2002).

11 Confronte Nota 9, que explica como foram identificadas as línguas maternas dos sujeitos inquiridos.

12 Os dados sobre língua materna dos inquiridos foram obtidos a partir de um inquérito sociolinguístico, que incluía, entre outros aspetos, o perfil dos indivíduos, nomeadamente o nome, idade, sexo, língua materna do inquirido, língua materna dos pais, habilitações literárias, contexto de aprendizagem ou aquisição do Português (escola7casa).Assim, a língua materna dos inquiridos consta da tabela 2 deste artigo. Os resultados destes dados constam da tese defendida para a obtenção do grau de Doutor em Linguística. 
Kimwani (35,7\%); Shingoni (27,3\%); Shimakonde (11\%), Emakhuwa (3,2\%), com maior proporção para os do primeiro grupo. A Tabela 3, que se segue, ilustra a variação do comportamento linguístico dos inquiridos no ambiente doméstico de acordo com a língua materna.

Tabela 3 - Usos linguísticos em ambientes domésticos de acordo com a língua materna declarada pelos indivíduos

\begin{tabular}{lcccccccc}
\hline $\begin{array}{c}\text { Língua } \\
\text { materna }\end{array}$ & Usa LM & \multicolumn{2}{c}{ Não usa LM } & \multicolumn{2}{c}{$\begin{array}{c}\text { Não } \\
\text { Aplicável }\end{array}$} & \multicolumn{2}{c}{ Total } \\
\hline Português & 7 & 100 & 0 & 0 & 0 & 0 & 7 & 100 \\
\hline Emakhuwa & 548 & 96,3 & 18 & 3,2 & 3 & 1 & 569 & 100 \\
\hline Shimakonde & 39 & 86,7 & 6 & 13,3 & 0 & 0 & 45 & 100 \\
\hline Shingoni & 16 & 72,7 & 6 & 27,3 & 0 & 0 & 22 & 100 \\
\hline Kiswahili & 5 & 100 & 0 & 0 & 0 & 0 & 5 & 100 \\
\hline Kimwani & 9 & 47 & 5 & 35,7 & 5 & 26,3 & 19 & 100 \\
\hline
\end{tabular}

Fonte: Elaboração própria.

Para melhor visualizar a tendência do comportamento linguístico dos informantes em ambientes caseiros, vejamos o Gráfico que a seguir se apresenta, o qual sintetiza os dados inseridos na Tabela 3.

Gráfico 1 - Usos linguísticos em ambientes domésticos de acordo com a língua materna declarada pelos indivíduos

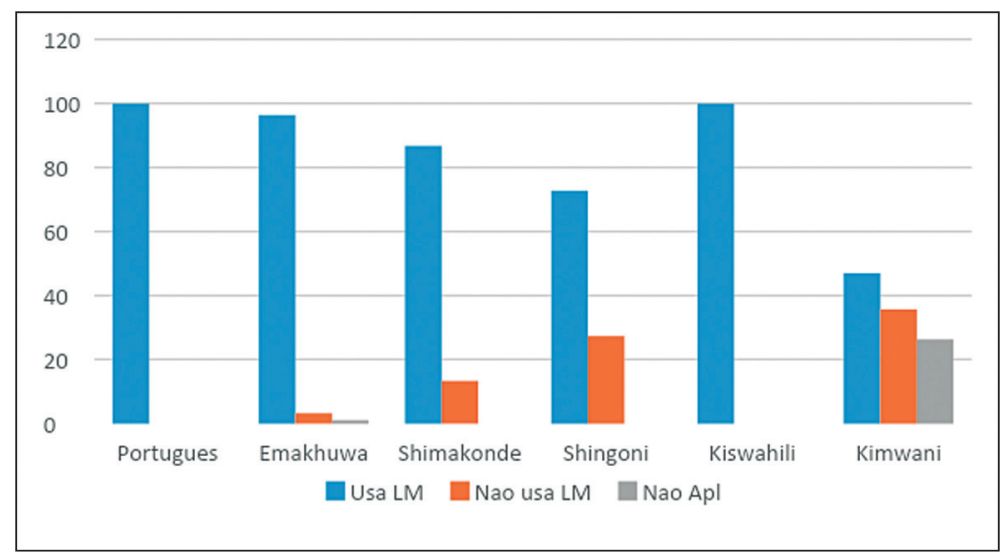

Fonte: Elaboração própria. 
Apesar desta relativa preferência pelas línguas maternas, os dados mostram que os inquiridos tendem a usar outras línguas não maternas para se comunicarem em ambientes domésticos, principalmente Emakhuwa, Português e Kiswahili, conforme ilustra a Tabela 4, que se segue:

Tabela 4 - Uso de línguas não maternas em ambientes domésticos

\begin{tabular}{lccccccccccccc}
\hline \multicolumn{1}{c}{ L1 } & \multicolumn{2}{c}{ Português } & \multicolumn{2}{c}{ Emakhuwa } & \multicolumn{2}{c}{ Shimakonde } & \multicolumn{2}{c}{ Shingoni } & \multicolumn{2}{c}{ Kiswahili } & \multicolumn{2}{c}{ Kimwani } \\
\hline & fr. & $\%$ & fr. & $\%$ & fr. & $\%$ & fr. & $\%$ & fr. & $\%$ & fr. & $\%$ \\
\hline Português & 0 & 0 & 3 & 43 & 0 & 0 & 0 & 0 & 0 & 0 & 0 & 0 \\
\hline Emakhuwa & 98 & 17 & 0 & 0 & 7 & 1,2 & 4 & 0,7 & 4 & 0,7 & 4 & 0,7 \\
\hline Shimakonde & 20 & 44 & 7 & 16 & 0 & 0 & 1 & 2,2 & 12 & 27 & 3 & 6,7 \\
\hline Shingoni & 7 & 31,8 & 15 & 68,2 & 1 & 4,5 & 0 & 0 & 4 & 18,2 & 2 & 9,1 \\
\hline Kiswahili & 3 & 60 & 2 & 40 & 0 & 0 & 0 & 0 & 0 & 0 & 0 & 0 \\
\hline Kimwani & 5 & 35,7 & 3 & 21,4 & 5 & 35 & 0 & 0 & 2 & 14,3 & 0 & 0 \\
\hline
\end{tabular}

Fonte: Elaboração própria.

Como se pode notar na tabela acima, (1) alguns inquiridos cujas L1 é Português (43\%), Shimakonde (16\%), Shingoni (68,2\%), Kiswahili (40\%) e Kimwani $(21,4 \%)$ afirmaram que usavam Emakhuwa; (2) muitos inquiridos, cujas LMs são Emakhuwa (17\%), Shimakonde (44\%), Shingoni (31,8\%), Kiswahili (60\%) e Kimwani (35,7\%) disseram que usavam Português; por último, (3) alguns segmentos consideráveis de falantes do Shimakonde (27\%), Shingoni $(18,2 \%)$ e Kimwani $(14,3 \%)$ como L1 disseram que usavam Kiswahili no ambiente doméstico.

\section{Breve análise e interpretação dos resultados}

Após a apresentação dos resultados do inquérito, segue a sua análise. $\mathrm{O}$ ambiente doméstico, neste estudo identificado como casa, é um domínio informal, uma vez que nele ocorrem interações entre membros da família, tratando assuntos do quotidiano. Deste modo, conforme a hipótese anteriormente colocada, pressupõe-se que em ambiente informal como casa sejam usadas exclusivamente as línguas bantu, que identificam as diferentes famílias, como até é assumido na literatura que se debruça sobre o assunto (FIRMINO, 2002; NGUNGA; BAVO 2011; ADAMS; MATU; ONGARORA, 2012).

Embora as tendências gerais indiquem maior uso do Emakhuwa e do Português nas interações verbais em ambientes caseiros, os dados dispostos por L1 mostram que muitos inquiridos tendem a usar a sua língua materna (que inclui o Português) para se comunicarem neste domínio informal. O Português é, por conseguinte, língua materna de alguns inquiridos, podendo ser usado em casa. Importa sublinhar que, apesar de o número dos seus falantes como L1 ser menos expressivo, apenas 7 (cf. Tabela 3), todos 
disseram que usavam o Português em ambientes caseiros, o que revela presença forte da língua oficial inclusive neste domínio informal. Por outro lado, o Português é também usado em ambientes domésticos por falantes que têm as LBs como línguas maternas. Estes resultados levam-me a aferir que, neste domínio, o Português é também uma língua da informalidade, contrariando autores como Firmino (2002) e Ngunga e Bavo (2011), que reservam este contexto apenas paras as línguas bantu. Estudos similares mostram ascendência de línguas tidas como High na interação com os filhos no ambiente doméstico como resultado de language shift (MGBEMENA, 2014; ADAMS; MATU; ONGARORA, 2012).

Quanto ao uso das línguas maternas de origem bantu em ambientes caseiros, excetua-se o caso de muitos inquiridos cuja L1 é Kimwani, que declararam que usavam Emakhuwa e Português, pelo que considerámos um caso diferente. De facto, esta é uma tendência não normal para o caso do ambiente familiar os inquiridos não recorrerem à sua língua materna, isto é, no caso em que não se segue a tendência normal, os dados mostram que os informantes tendem a recorrer ou ao Emakhuwa ou ao Português. Esta constatação atesta um fenómeno importante, o da mudança de língua para o Emakhuwa, portanto para uma língua autóctone maioritária ou para o Português, língua oficial em Moçambique. Com base no comportamento linguístico dos inquiridos falantes do Kimwani como L1, pode aferir-se que há um indício de que, havendo o fenómeno de language shift (GAL, 1979; FASOLD, 1984), a tendência é para a aquisição ou aprendizagem e uso da língua predominante na região (neste caso Emakhuwa ou Português). Deste modo, pode assumir-se que, em Montepuez, Emakhuwa e Português constituem as línguas que a maioria das pessoas procura aprender para se comunicarem inclusive no ambiente doméstico, nas interações entre familiares.

A aferição feita no parágrafo anterior baseia-se, por outro lado, no fato de alguns inquiridos cuja L1 é Português, Shimakonde, Shingoni, Kiswahili e Kimwani declararem que usavam também Emakhuwa, para além das suas línguas maternas. Constatouse também que muitos inquiridos, falantes do Emakhuwa, Shimakonde, Shingoni, Kiswahili e Kimwani como línguas maternas declararam que usavam também o Português em casa. Em contrapartida, os resultados indicam que a grande maioria dos inquiridos cuja L1 é Emakhuwa não recorre às restantes línguas bantu para se comunicarem em casa, privilegiando a escolha da LM ou do Português, o que pode ser analisado com base nas teorias sobre atitudes linguísticas.

Com base nos dados do inquérito, pode aferir-se que o padrão de escolhas linguísticas em ambientes domésticos de Montepuez consiste, basicamente, no uso de duas a três línguas, destacando-se a língua materna, que inclui o Português. Assim, os falantes do Emakhuwa como língua materna tendem a usar, fundamentalmente, duas línguas, enquanto os falantes de outras línguas tendem a usar, basicamente, três línguas em ambientes domésticos.

Como foi referido, no ambiente caseiro, não só se usa as línguas bantu como também o Português, o que significa que, o que é mais expectável é o uso da língua materna, que pode incluir o Português. Este facto leva-nos a concluir que, no contexto de Montepuez, 
a língua materna desempenha um papel importante no comportamento linguístico dos informantes nas suas interações nos domínios informais, particularmente nos ambientes caseiros. Esta constatação é importante porque nos obriga a uma reavaliação dalguns pressupostos teóricos a que se recorre para explicar o fenómeno de escolha linguística. Por exemplo, a noção da diglossia (FISHMAN, 1967b) pressupõe uma dicotomia entre língua $\mathrm{H}$ e língua $\mathrm{L}$, assumindo-se que haveria línguas para os domínios altos e línguas para os domínios baixos. No contexto de Montepuez, o caso do Português, que é usado em domínios informais como casa contraria esta pressuposição.

Embora, no contexto moçambicano, a língua portuguesa seja eminentemente uma língua $\mathrm{H}$, dado o seu estatuto de língua oficial, tendo em conta os resultados do presente estudo, pode assumir-se que também é usada em domínios informais, podendo, portanto funcionar como uma língua L. Estes resultados permitem-me aferir ainda que, no contexto multilingue de Montepuez, o estudo do uso da língua High e da língua Low não é necessariamente e/ou mutuamente excludente. Por conseguinte, e tendo em conta os resultados de estudos similares (RUBIN, 1968; ELLIS; URE, 1982; FLINT, 1972), a pertinência da revisão da dicotomia que envolve as noções língua High e língua Low no estudo das escolhas linguísticas sobretudo em contextos multilingues surge como um desafio da Sociolinguística na atualidade. Por outro lado, os resultados do presente estudo obrigam também a uma reavaliação do conceito de "língua materna" que, segundo o senso comum, e tendo em conta o contexto de Moçambique, remete apenas às línguas moçambicanas de origem bantu, encarando o Português como uma língua exógena, como se não tivesse falantes nativos em Moçambique e como se não fosse usado nos domínios mais baixos de interação social em que os falantes se engajam.

\section{Conclusão}

Procurei, neste artigo, mostrar que no contexto multilingue de Montepuez, a língua materna, que inclui o Português para muitos falantes, desempenha um papel fundamental na interação entre membros familiares em ambientes caseiros. O estudo mostrou que, se é verdade que se nota o uso de línguas bantu no ambiente doméstico, não é menos verdade que se constata também o uso do Português tanto como L1 (em pouco número de casos em virtude do reduzido número de informantes) quanto como L2 (de forma bem mais produtiva), num domínio que, do ponto de vista teórico, está reservado às línguas encaradas como baixas. No contexto de Moçambique, o uso do Português em ambiente caseiro pode ser encarado como menos comum, por incluir informantes que o declaram como L2. Esta conclusão reforça, por si só, a ideia de que o contexto real de interação determina a escolha linguística, e não necessariamente a rigidez ditada pelos pressupostos teóricos da escolha linguística.

Tendo em conta as conclusões a que fiz referência e, com base nos resultados deste estudo, a tese principal que o presente trabalho procurou afirmar é que, no contexto de Montepuez, tanto o Português quanto às línguas bantu, nomeadamente Emakhuwa, 
Shimakonde, Shingoni, Kiswahili e Kimwani como línguas maternas desempenham um papel fundamental na comunicação entre os membros familiares em ambientes caseiros. No entanto, assumimos, neste estudo, que, em Montepuez, o repertório linguístico de muitos falantes é constituído, fundamentalmente, por três línguas, sendo que o Português é usado como L1, ou como L2. Portanto, quando o informante não usa a língua materna (língua bantu), tende a usar o Português ou a língua indígena franca local, nomeadamente o Emakhuwa. Este fenómeno poderá ser melhor explicado recorrendo a estudos virados para a variação das escolhas linguísticas de acordo com o interlocutor, conforme se trate de filhos, pais, tios ou avós, etc.

Assim, do ponto de vista teórico, podemos dizer que o contributo do presente trabalho de investigação reside no fato de mostrar que a questão da seleção linguística em contexto multilingue não pode ser tratada recorrendo a uma perspetiva reducionista, ou seja, baseada apenas numa única abordagem. No entanto, como disse na síntese relativa a exemplos de estudos orientados pelas noções de diglossia e de domínio, as diferentes abordagens sobre a escolha linguística não se contradizem. $\mathrm{O}$ facto é que nenhuma é bastante e suficientemente forte para explicar o fenómeno. $\mathrm{O}$ ato comunicativo é, de fato, um processo negocial, em que as opções linguísticas são o resultado de uma negociação, que ocorre durante, não antes ou depois, do referido ato comunicativo. Recomendam-se, assim, estudos destinados à investigação no campo das atitudes linguísticas dos falantes, para complementar as pesquisas sobre escolhas linguísticas, podendo ser realizados não só em Montepuez/Cabo Delgado, como em outras regiões de Moçambique.

LINDONDE, M. The question of linguistic choice in domestic environments in a multilingual context of Mozambique. Alfa, São Paulo, v.65, 2021.

- ABSTRACT: The present study examined the patterns of linguistic choices in domestic environments in Montepuez, Mozambique, based on sociolinguistics approaches that deal with linguistic selection in multilingual contexts, namely the notions of diglossia and domain. The data collected through a survey. The study noted that the various languages are used in home environments, with a greater predominance of Portuguese and Emakhuwa, with no relation between the formality and the informality of the situation. Thus, in the home environment, the trend is the use of mother tongues, which include Portuguese. From a theoretical point of view, the study concluded that no approach is quite sufficiently strong to explain the phenomenon of linguistic choice in its entirety, calling for a more integrated approach. It was observed that the real context of communication is built as the interaction takes place, so it is considered a negotiation process, which occurs during and not before or after the communicative act. Studies on linguistic choices in other territorial spaces in the province of Cabo Delgado are proposed, including those subordinated to linguistic attitudes aiming to expand the information on the factors that influence linguistic uses both in Montepuez and in other regions of the province.

- KEYWORDS: Multilingualism. Montepuez. Linguistic choice. Home environment. 


\section{REFERÊNCIAS}

ADAMS, Y.; MATU, P. M.; ONGARORA, D. O. Language use and choice: A case study of Kinubi in Kibera, Kenya. International Journal of Humanities and Social Science, Nairobi, v.2, n.4, p. 99-104, 2012.

APPEL, R.; MUYSKEN. Language Contact and Bilinguism. London: Edward Arnold, 1987.

ASSEMBleia DA RePÚBliCA. Constituição da República de Moçambique. Maputo: Escolar Editora, Editores e Livreiros, 2004.

BLOM, J.P.; GUMPERZ, J. Social meaning in linguistic structure: code switching in Norway. In: GUMPERZ, J.; HYMES, D. (org.). Directions in sociolinguistics: The Ethnography of Communication. New York: Wiley-Blackwell, 1972. p.407-434.

BORBÉLY, A. The Process and the Factors of Language Shift and Maintenance: A Sociolinguistic Research in the Romanian Minority Community in Hungary. Research Support Schame, Budapest, p.1-77, 2000.

COMPANHiA, C. A. Aquisição do Português em Moçambique: Papel do Contexto Social no Desenvolvimento Linguístico de Alunos da $7^{\text {a }}$ classe. 2016. Tese (Doutoramento em Linguística) - Faculdade de Letras e Ciências Sociais, Universidade Eduardo Mondlane, Maputo, 2016.

DERSINGH, R. Patterns of Language Choice in a Thai-Sikh Community in Bangkok. Bangkok: Faculty of Arts, Chulalongkorn Universy, 2014. PhD candidate.

DUMANIGE, F. P. et al. Language Choice and language policies in Filipino-Malaysian Families in Multilingual Malaysia. Journal of Multilingual and Multicultural Development, v.34, n.6, p. 582-596, 2013.

ELLIS, J.; URE, J.N. Register range and change. International Journal of Language, The Hague, n. 35, 1982.

FASOLD, R. The Sociolinguistics of Society. New York: Basil Bleckwell, 1984.

FERGUSON, C. A. Diglossia. Language and Social Strutures, v. 15, p. 232-251, 1959.

FIRMINO, G. A “Questão Linguística” na África pós-colonial: o caso do português e das línguas autóctones em Moçambique. Maputo: Promédia, 2002. (Colecção Identidades).

FIRMINO, G. Língua e Educação em Moçambique. In: TUZINE, A. Uso das Línguas Bantu no Ensino. Maputo: INDE, 1998. (Cadernos de Pesquisa, n.26).

FISHMAN, J. A. Domains and the relationship between micro-and macrosociolinguistics. In: GUMPERZ, J.J.; HYMES, D. (org.). Directions in sociolinguistics: The ethnography of communication. Oxford: Basil Blackwell, 1972. p. 435-453. 
FISHMAN, J. A. Bilingualism with and without diglossia; diglossia with and without bilingualism. Journal of Social Issues, Malden, v.23, n. 2, p. 29-38, 1967 a.

FISHMAN, J. A. The description of societal bilinguism. In: KELLY, L. G. (org.). The Description and Measurement of Bilinguism. Toronto: Toronto University Press, $1967 \mathrm{~b}$.

FISHMAN, J. A. Who speaks what language to whom and when? La Linguistique, Paris, v.1, p.67-88, 1965.

FLINT, E. H. Sociology of Language in Queensland Aboriginal Community. 1972. FORTIN, M. F.; CÔTÉ, J.; VISSANDJÉE, B. O Processo de Investigação: da concepção à realização. Loures: Lusociência, 1999.

GAL, S. Language shift: Social determinants of linguistic change in bilingual Austria. New York: Academic Press Inc, 1979.

GREENFIELD, P. M. Situational Measures of Normative Language View in Relational to Person, Place and Topic Among Puerto Rican Bilinguals. In: FISHMAN, J. (org.). Advances in the Sociology of Language. The Hague: Mouto, 1972. p.17-35.

HABERLAND, H. Domains and domains loss. In: PREISLER, B. et al. (ed.). Consequence of Mobility. Roskild: Roskild University, Department of Language and Culture, 2005. p.277-237.

HEINE, B. Language Policy in Africa. In: WEINSTEIN, B. (org.). Language Policy and Political Development. New Jersey: Ablex Publishing Corporation, 1990. p.167184.

INE. III Recenseamento Geral da População e Habitação 2007: Resultados Definitivos. Maputo, 2010.

LANDWEER, L. M. Endangered languages: Indicators of ethnolinguistic vitality. SIL International, 2008.

LINDONDE, L. M. As Relativas Locativas e Outras Construções Aparentadas, Introduzidas pelos Morfemas "Onde" e "Em Que" no Português de Moçambique. 2002. Dissertação (Mestrado em Letras) - Faculdade de Letras, Universidade do Porto, Porto, 2002.

LINDONDE, L.M. Padrões de Escolhas Linguísticas num Contexto Multilingue de Moçambique: O Caso de ontepuez, em Cabo Delgado. Tese (Doutorado em Linguística) - Faculdade de Letras e Ciências Sociais, Universidade Eduardo Mondlane, Maputo, 2018.

LOPES, A.J. Língua Portuguesa em Moçambique: Timakas, milandos e desafios. Revista Brasileira, Rio de Janeiro, v.74, p.117-134, 2013. 
MAE. Perfil do Distrito de Montepuez Província de Cabo Delgado. Série Perfis Distritais. Maputo, 2005.

MGBEMENA, J. The Sociology of Nigerian English: Trends in English Usege in Aba Example. International Journal of English Linguistics, Wukari, v.4, 2014.

NGUNGA, A.; BAVO, N. Práticas Linguísticas em Moçambique: Avaliação da Vitalidade Linguística em Seis Distritos. Maputo: Centro de Estudos Africanos/UEM, 2011. (Colecção As nossas línguas, IV).

PARASHER, S. N. Mother-tongue. English diglossia: A case study of educated Indian bilinguals language use. Anthropological Linguistics, Bloomington, p. 151-168, 1980.

PETZELL, M. The linguistic situation in Tanzania. Moderna Sprak, Gothenburg, p. 136-144, 2012.

RUBIN, J. National Bilingualism in Paraguay. The Hague: Mouton, 1968.

STEPKOWSKA, A. Diglossia: A Critical Overview of the Swiss Example. Studia Linguistica Universitati Lagellonicae Cracovlensis, Warsawi, p. 199-209, 2012.

VILELA, M. Reflexões sobre a política linguística nos PALOP (Países de Língua Oficial Portuguesa). Africana Studia, Porto, n.4, 2001.

WHERRIT, I. Portuguese language use in Goa, India. Anthropological Linguistics, Bloomington, v. 27, n. 4, p.437-451, 1985.

Recebido em 14 de abril de 2019

Aprovado em 3 de junho de 2020 